\title{
A synthetic system links FeFe-hydrogenases to essential E. coli sulfur metabolism
}

\author{
Buz Barstow ${ }^{1,2}$, Christina M Agapakis ${ }^{1+}$, Patrick M Boyle ${ }^{1 \dagger}$, Gerald Grand ${ }^{1+}$, Pamela A Silver $^{1,2^{*}}$ and \\ Edwin $\mathrm{H}_{\text {Wintermute }}{ }^{1}$
}

\begin{abstract}
Background: FeFe-hydrogenases are the most active class of $\mathrm{H}_{2}$-producing enzymes known in nature and may have important applications in clean $\mathrm{H}_{2}$ energy production. Many potential uses are currently complicated by a crucial weakness: the active sites of all known FeFe-hydrogenases are irreversibly inactivated by $\mathrm{O}_{2}$.

Results: We have developed a synthetic metabolic pathway in E. coli that links FeFe-hydrogenase activity to the production of the essential amino acid cysteine. Our design includes a complementary host strain whose endogenous redox pool is insulated from the synthetic metabolic pathway. Host viability on a selective medium requires hydrogenase expression, and moderate $\mathrm{O}_{2}$ levels eliminate growth. This pathway forms the basis for a genetic selection for $\mathrm{O}_{2}$ tolerance. Genetically selected hydrogenases did not show improved stability in $\mathrm{O}_{2}$ and in many cases had lost $\mathrm{H}_{2}$ production activity. The isolated mutations cluster significantly on charged surface residues, suggesting the evolution of binding surfaces that may accelerate hydrogenase electron transfer.
\end{abstract}

Conclusions: Rational design can optimize a fully heterologous three-component pathway to provide an essential metabolic flux while remaining insulated from the endogenous redox pool. We have developed a number of convenient in vivo assays to aid in the engineering of synthetic $\mathrm{H}_{2}$ metabolism. Our results also indicate a $\mathrm{H}_{2}{ }^{-}$ independent redox activity in three different FeFe-hydrogenases, with implications for the future directed evolution of $\mathrm{H}_{2}$-activating catalysts.

\section{Background}

Nature provides a catalyst for $\mathrm{H}_{2}$ production: hydrogenase metalloenzymes[1]. Hydrogenase active sites are composed only of widely available metals, yet can reduce protons to $\mathrm{H}_{2}$ more rapidly than platinum catalysts[2]. They have therefore been proposed as a substitute for precious metal electrodes for the low-cost, highvolume interconversion of electricity and $\mathrm{H}_{2}[2,3]$. Enzymatic catalysts are particularly well-suited for synthetic integration with specifically biological energy sources. For example, coupling of hydrogenase enzymes with the photosynthetic machinery enables the direct production of $\mathrm{H}_{2}$ from sunlight, as has been demonstrated both in vitro[4] and in vivo[5,6].

\footnotetext{
* Correspondence: pamela_silver@hms.harvard.edu

+ Contributed equally

'Department of Systems Biology, Harvard Medical School, Boston MA 02115, USA

Full list of author information is available at the end of the article
}

Several classes of hydrogenases are found in nature[1], distinguished primarily by the metal content of their active site. These enzymes vary widely with respect to their activity level, maturation requirements, redox partners and $\mathrm{O}_{2}$ tolerance, all of which affect their potential biotechnological utility.

Here we employ iron-iron ( $\mathrm{FeFe}$ ) hydrogenases of the monomeric, cytosolic class found widely in nature and common among the Clostridia[7]. These are the biochemically best-characterized hydrogenases, featuring a well-defined set of maturation factors that are sufficient for their heterologous expression in engineered organisms $[8,9]$. Members of this class exhibit among the highest activities of known hydrogenases, with catalytic rates exceeding the $1000 \mathrm{nmol} \mathrm{H}_{2} \mathrm{mg}^{-1} \mathrm{~min}^{-1}$ estimated to be required for efficient in vivo photosynthetic $\mathrm{H}_{2}$ production[10]. However, biotechnological applications of FeFe-hydrogenases are impeded by the rapid and irreversible inactivation of the active site by $\mathrm{O}_{2}[11]$.
C Biomed Central

C 2011 Barstow et al.; licensee BioMed Central Ltd. This is an open access article distributed under the terms of the Creative Commons Attribution License (http://creativecommons.org/licenses/by/2.0), which permits unrestricted use, distribution, and reproduction in any medium, provided the original work is properly cited. 
In contrast, several naturally occurring hydrogenases of the nickel-iron (NiFe) class[12-15] and the nickeliron-selenium (NiFeSe) class[16] are known to be $\mathrm{O}_{2}$ tolerant. However, the $\mathrm{H}_{2}$ production rates of NiFehydrogenases are 10 to 1000 times slower than FeFehydrogenases[1,17,18]. The maturation requirements for NiFe-hydrogenases are also relatively complex, with as many as 13 genes required for heterologous $[1,17,18]$ reconstitution in some cases[19], limiting their facility of heterologous expression.

There is currently no known hydrogenase of any class that produces $\mathrm{H}_{2}$ at rates comparable to the FeFehydrogenases and is tolerant of $\mathrm{O}_{2}$. However, both the activities and $\mathrm{O}_{2}$ tolerance of naturally occurring FeFehydrogenases span wide ranges and are uncorrelated [20]. $\mathrm{O}_{2}$ sensitivity may even be adaptive in hydrogenase evolution, acting as a form of regulation[21,22]. If the natural selective pressure for $\mathrm{O}_{2}$ tolerance is weak, it should be possible to engineer a hydrogenase with both high activity and improved $\mathrm{O}_{2}$ tolerance.

Recent results suggest structural modifications that may alter hydrogenase $\mathrm{O}_{2}$ tolerance. Widening a gas channel, through which $\mathrm{H}_{2}$ is believed to approach the active site, resulted in the loss of $\mathrm{O}_{2}$ tolerance in a Ralstonia eutropha NiFe-hydrogenase[23]. Similarly, the mutation of gas channel residues in a Desulfovibrio fructosovorans $\mathrm{NiFe}$-hydrogenase increases $\mathrm{O}_{2}$ tolerance yet only moderately reduces catalytic activity[24]. Although understanding of the mechanism of $\mathrm{O}_{2}$-inactivation of hydrogenases has greatly improved $[25,26]$ it has not yet been possible to rationally design mutations to improve $\mathrm{O}_{2}$ tolerance without impairing activity.

Directed evolution permits the optimization of function without detailed knowledge of enzyme mechanism $[27,28]$. This technique entails either screening or genetically selecting for desirable mutants from suitably large mutation libraries. In vitro screens for hydrogenase activity are capable of assaying $10^{3}-10^{4}$ hydrogenase mutants per day [29]. Yet double or triple combinatorial point mutation libraries for a gene the size of the hydrogenase approach $10^{7}-10^{10}$ unique sequences, and can not be comprehensively screened with existing methods. Genetic selection is the most powerful available tool for the rapid and economical parsing of very large mutation libraries. This technique requires a connection between a desired enzyme property and the evolutionary fitness of a strain expressing the enzyme.

We have engineered an artificial pathway in $E$. coli connecting hydrogenase function to the production of sulfide, an essential precursor of the amino acids cysteine and methionine. We address two design objectives that maximize the utility of this system for directed evolution. First, we minimize pathway activity independent of the hydrogenase, insulating redox interactions with native metabolism and reducing the potential for selection false positives. Second, we maximize hydrogenase-dependent activity of the pathway, creating a robust link to host fitness by ensuring binding compatibility between synthetic pathway components. Because genetic selection can be performed only in vivo, we have optimized the biochemistry of our pathway in vivo. This pathway forms the basis of a genetic selection for $\mathrm{O}_{2}$ tolerant hydrogenases.

\section{Methods}

\section{Cloning and gene synthesis}

All cloning was performed in E. coli DH5 $\alpha$ using standard BioBrick assembly techniques[30]. Final constructs were assembled in commercial Duet vectors (Novagen) with multiple cloning sites modified to accept BioBrick parts. The plasmids used in these experiments are listed in table 1. Complete vector sequences are provided in additional file 1 .

The hydrogenase genes hydA1 from Clostridium acetobutylicum ATCC 824 and hydA from Clostridium saccharobutylicum P262 were cloned from plasmids received from Matthew Posewitz (National Renewable Energy Laboratory, Golden, CO, USA). Dr. Posewitz also provided plasmids bearing the $C$. acetobutylicum maturation factors $h y d E$, hydF, and hydG[31]. The hydrogenase maturation factors hydEF and hydG from Chlamydomonas reinhardtii were commercially synthesized by Codon Devices. The por gene encoding pyruvate-ferredoxin oxidoreductase from Desulfovibrio africanus was cloned from plasmid pLP1[32] provided by Laetitia Pieulle (Centre National de la Recherche Scientifique, Marseille, France). Clostridium acetobutylicum ferredoxin CAC0303[33] was cloned from genomic DNA (ATCC 824). Spinacia oleracea ferredoxin (GenBank AAA34028), Zea mays ferredoxin (GenBank ACA34367) and Zea mays sulfite reductase (GenBank BAA23641) were cloned from total RNA. The ferredoxin-NADPH reductase (FNR) gene from Zea mays (GenBank AAB40034) was synthesized by Codon Devices. Chloroplast transit peptides were omitted from all plant-derived constructs. The codon usage of synthetic genes was optimized by the manufacturer for heterologous expression.

\section{Gene expression}

All synthetic pathways were expressed in strains derived from E. coli BL21(DE3), obtained from Agilent Technologies. Plasmids were maintained through selective antibiotics: ampicillin, $50 \mu \mathrm{g} / \mathrm{mL}$; spectinomycin, $25 \mu \mathrm{g} / \mathrm{mL}$; kanamycin, $25 \mu \mathrm{g} / \mathrm{mL}$; chloramphenicol, $12.5 \mu \mathrm{g} / \mathrm{mL}$. Protein expression from the Duet vectors was T7-promoter driven and induced with IPTG at a concentration of $1 \mathrm{mM}$. 
Table 1 Plasmids used in this study

\begin{tabular}{|c|c|c|c|c|c|}
\hline \multirow{2}{*}{\multicolumn{2}{|c|}{$\begin{array}{l}\text { Name } \\
\text { Hydrogenase activity in vivo }\end{array}$}} & Constructs & \multirow[t]{2}{*}{ Backbone } & \multirow[t]{2}{*}{ Resistance } & \multirow[t]{2}{*}{ Source } \\
\hline & & & & & \\
\hline pET.mp1 & caHydE & caHydA & pETDuet-1 & Ampicillin & Matthew Posewitz[31] \\
\hline pCDF.mp2 & $\mathrm{caHydF}$ & caHydG & pCDFDuet-1 & Spectinomycin & Matthew Posewitz[31] \\
\hline pACYC.ew3 & daPFOR & & pACYCDuet-1 & Chloramphenicol & This work \\
\hline pACYC.ew4 & daPFOR & soFD & pACYCDuet-1 & Chloramphenicol & This work \\
\hline pACYC.ew5 & daPFOR & $z m F D$ & pACYCDuet-1 & Chloramphenicol & This work \\
\hline pACYC.ew6 & daPFOR & $\mathrm{crFD}$ & pACYCDuet-1 & Chloramphenicol & This work \\
\hline pACYC.ew7 & daPFOR & caFD & pACYCDuet-1 & Chloramphenicol & This work \\
\hline pACYC.ew8 & soFD & & pACYCDuet-1 & Chloramphenicol & This work \\
\hline pACYC.ew9 & $z m F D$ & & pACYCDuet-1 & Chloramphenicol & This work \\
\hline pACYC.ew10 & crFD & & pACYCDuet-1 & Chloramphenicol & This work \\
\hline pACYC.ew11 & caFD & & pACYCDuet-1 & Chloramphenicol & This work \\
\hline \multicolumn{6}{|c|}{ FNR-supported growth ${ }^{B}$} \\
\hline pCDF.ew12 & zmFNR & & pCDFDuet-1 & Spectinomycin & This work \\
\hline pACYC.ew13 & soFD & $z m S I R$ & pACYCDuet-1 & Chloramphenicol & This work \\
\hline pACYC.ew14 & $z m F D$ & $z m S I R$ & pACYCDuet-1 & Chloramphenicol & This work \\
\hline pACYC.ew15 & $\mathrm{CrFD}$ & $z m S I R$ & pACYCDuet-1 & Chloramphenicol & This work \\
\hline pACYC.ew16 & caFD & $z m S I R$ & pACYCDuet-1 & Chloramphenicol & This work \\
\hline pACYC.ew17 & zmSIR & & pACYCDuet-1 & Chloramphenicol & This work \\
\hline \multicolumn{6}{|c|}{ Hydrogenase-supported growth and selection ${ }^{c}$} \\
\hline pACYC.ew18 & CrHydEF & $\mathrm{crHydG}$ & pACYCDuet-1 & Chloramphenicol & This work \\
\hline pET.ew19 & soFD & $z m S I R$ & pETDuet-1 & Ampicillin & This work \\
\hline pCDF.ew20 & $\mathrm{CrHydA}$ & & pCDFDuet-1 & Spectinomycin & This work \\
\hline pCDF.ew21 & caHydA & & pCDFDuet-1 & Spectinomycin & This work \\
\hline pCDF.ew22 & csHydA & & pCDFDuet-1 & Spectinomycin & This work \\
\hline
\end{tabular}

Duet vector backbones (Novagen) were used for all protein expression. Complete vector sequences are provided in additional file 1 . A) Plasmids mp1-ew11 were used to generate PFOR-driven hydrogenase activity data for Figure 4. B) Plasmids ew12-ew17 were used to assess knockout strain insulation for Figure 2. They were also used to measure ferredoxin performance in Figure 4. C) Plasmids ew18-ew22 facilitated the hydrogenase $\mathrm{O}_{2}$ tolerance measurements in Figure 3. They were also used in the hydrogenase-supported growth curves in Figure 5 and for the genetic selection.

\section{Gene deletions}

Sequential gene deletions were constructed by P1 phage transduction from the Keio collection[34]. Serial deletions were enabled by removing the transduced kanamycin resistance marker though homologous recombination at flanking FRT sites. Transient expression of the Flp recombinase was facilitated by the 705-Flp plasmid, which exhibits temperature-sensitive recombinase expression and a temperature-sensitive replication origin [35]. Kanamycin marker integration and subsequent removal was confirmed for all loci by PCR.

\section{Selective and induction media}

Selective media was a standard M9 formulation, supplemented with additional glucose, sulfate, ferric iron and a rich mix of supplements less cysteine and methionine. Induction media for hydrogenase expression was LB with added glucose, ferric iron, phosphate buffer and Baker's antifoam reagent. Exact media recipes are provided in additional file 2 .

\section{Anaerobic technique and custom atmospheres}

Anaerobic liquid culture was performed in $40 \mathrm{~mL}$ serum vials sparged with $\mathrm{N}_{2}$ and sealed with SubaSeal ${ }^{\mathbb{R}}$ rubber septa (Sigma-Aldrich). To maintain anaerobiosis during handling, samples were drawn and reagents added by piercing the septa with non-coring syringe needles.

Agar plates were incubated under defined gas mixtures within sealed Vacu-Quick jars (Almore International). The ambient atmosphere was removed by several cycles of evacuation and replacement with pure $\mathrm{N}_{2}$ before supplying a custom atmosphere. Aluminosilicate desiccant packets were added to prevent moisture accumulation within the jars.

\section{Growth assays}

Cells were grown to saturation in induction media and washed $3 \times$ with phosphate-buffered saline (PBS). Cells were resuspended in selective media at an initial $\mathrm{OD}_{600}$ of 0.01 . Final ODs were measured after 18 hours of 
growth at $37^{\circ} \mathrm{C}$. Anaerobic conditions, when appropriate, were introduced as described above.

\section{In situ hydrogenase activity assays}

Cells were grown to saturation in anaerobic induction media. Samples were drawn to determine cell density by OD. Fresh serum vials containing $25 \mathrm{~mL}$ of induction LB were anaerobically inoculated with $10^{8}$ cells $(\approx 5$ $\mathrm{mL}$ ). Following incubation at $37^{\circ} \mathrm{C}$ for 2 hours, $\mathrm{H}_{2}$ production was stopped by the addition $2 \mathrm{~mL}$ methanol. Accumulated headspace $\mathrm{H}_{2}$ was measured by gas chromatography (Shimadzu GC-14A).

\section{In vitro hydrogenase activity assays}

Hydrogenase activities were measured with a biochemical methyl viologen assay adapted from King et al. [9]. Hydrogenase-expressing $E$. coli were grown to saturation in $20 \mathrm{~mL}$ of induction media under anaerobic conditions. Samples were drawn to determine cell density by OD. Cells were lysed with $1 \mathrm{~mL}$ of lysis buffer consisting of $20 \mathrm{~mL}$ B-PER II protein extraction reagent (Thermo Scientific), $500 \mu \mathrm{L}$ Baker's antifoam B, 100 units DNAse I and $50 \mathrm{mg}$ dithionite. Antifoam and DNAse I were added to prevent foaming of the lysate. Dithionite served to scavenge dissolved $\mathrm{O}_{2}$ in the buffer. Lysis continued for 15 minutes under continuous $\mathrm{N}_{2}$ sparging. Lysed cultures were sealed and injected with $1 \mathrm{~mL}$ of methyl viologen assay buffer consisting of $20 \mathrm{~mL} 1 \mathrm{M}$ Tris at $\mathrm{pH} 8,300 \mathrm{mg}$ methyl viologen and $3 \mathrm{~g}$ dithionite. Following 2 hours of incubation at $37^{\circ} \mathrm{C}, \mathrm{H}_{2}$ production was stopped with $2 \mathrm{~mL}$ of methanol. Accumulated headspace $\mathrm{H}_{2}$ was measured by gas chromatography.

\section{Sulfide production assays}

Sulfide production was measured spectrophotometrically by the methylene blue method[36]. Bacteria were grown to saturation in selective media with IPTG and appropriate antibiotics, supplemented with $100 \mathrm{mg} / \mathrm{L}$ cysteine to allow growth of all strains. Cultures were diluted 1:50 to $25 \mathrm{ml}$ in $40 \mathrm{ml}$ sealed serum vials. Vials were flushed with either pure $\mathrm{N}_{2}$ or $40 \% \mathrm{H}_{2}$ in $\mathrm{N}_{2}$ and grown for 6 hours at $37^{\circ} \mathrm{C}$. Cuvettes were prepared with $2.5 \mathrm{~mL}$ assay solution containing N,N-Dimethyl-1,4-phenylenediammonium dichloride $(200 \mu \mathrm{M}), \mathrm{FeCl}(600 \mu \mathrm{M})$ and $\mathrm{HCl}(60 \mathrm{mM}) .25 \mu \mathrm{L}$ of filtered media was added to assay cuvettes and allowed to react for 1 hour. Absorbance was measured at $660 \mathrm{~nm}$ and compared to a standard curve to calculate sulfide concentrations. Statistics were inferred from three biological replicates.

\section{Hydrogenase $\mathrm{O}_{2}$ tolerance assays}

Hydrogenase half-lives in $\mathrm{O}_{2}$ were measured using an adaptation of the in vitro activity assay above. Following anaerobic lysis, a customized sparging apparatus was used to bubble $\mathrm{O}_{2}$ through the cultures at a constant partial pressure of 0.1 atm for defined time points between 5 and 25 minutes. Cultures were then flushed for 5 minutes with pure nitrogen before being sealed and assayed with methyl viologen assay buffer, as above. Measurements at each time point were taken for 3 biological replicates.

\section{Colony growth assays under custom atmospheres}

Cells were grown to saturation in induction media. Residual nutrients were removed by $3 \times$ washing with PBS. Cell densities were measured with a hemocytometer and diluted to a final concentration of $1 \mathrm{cell} / \mu \mathrm{L}$. Fifty microliters $(\approx 50$ cells) were dispensed onto selective plates and transferred to Vacu-Quick jars. The jars were filled with $15 \% \mathrm{H}_{2}, \mathrm{O}_{2}$ varying from $0-12.5 \%$, and a balance of $\mathrm{N}_{2}$ to a total internal pressure of $1 \mathrm{~atm}$. Incubation was carried out at $37^{\circ} \mathrm{C}$ for 72 hours. Plates were photographed in an inverted camera stage (Figure 5E). Colonies were identified and sized with an image analysis script implemented in MATLAB (MathWorks). Each data point represents size data collected from roughly 50 individual colonies.

\section{Hydrogenase mutagenesis and selection}

Mutation libraries were created through error-prone PCR amplification of the hydrogenase genes with the GeneMorph II Random Mutagenesis Kit (Agilent Technologies). Exact primer sequences are indicated in additional file 1 . The PCR products were digested with NotI and SpeI (for $c a \mathrm{HydA}$ ) or NcoI and NotI (for $c s \mathrm{HydA}$ ), purified, and ligated into a modified pCDFDuet- 1 vector (Novagen). A target frequency of 4.5 mutations/kb was sought according to the manufacturer's instructions and confirmed by sequencing several clones plated nonselectively.

Host cells were transformed with the mutant hydrogenase libraries by electroporation and recovered in SOC media for 1 hour at $37^{\circ} \mathrm{C}$. Following recovery, the cells were washed three times with Phosphate Buffered Saline (PBS) and plated on selective media. Approximately $10^{7}$ unique transformants were applied to each plate, as assessed by serial dilution of the recovered cells. Selection plates were then transferred to Vacu-Quick jars prepared as above with a selective atmosphere containing $10 \% \mathrm{O}_{2}$ and $15 \% \mathrm{H}_{2}$. Incubation proceeded at $37^{\circ} \mathrm{C}$ for 4 days.

Selection restreaks were performed using Petri dishes with internal divisions to block the diffusion of metabolites from neighboring streaks[37]. Soft plastic inoculating loops were used to prevent marring of the agar surface and maintain a uniformly oxic environment $[38,39]$. 


\section{Structure and surface modeling}

Homology models of hydrogenase mutants were constructed using SWISS-Model homology modeling service[40] using the Clostridium pasteurianum hydrogenase I structure[41] as a template (PDB ID: 3C8Y).

The protein surface was inferred with the NIH MBI Diffusion Accessibility Calculator[42]. The diffusion accessibility was averaged in a moving window of 5 residues, then thresholded to produce defined surfaceaccessible regions.

\section{Simulated mutation spectra}

The set of point mutations isolated by our genetic selection was compared to the expected distribution under a null model of no selective pressure. The null distribution was generated as a parallel Monte Carlo simulation implemented in PYTHON. Our algorithm produced $5 \cdot 10^{9}$ randomly mutated sequences for each $c a \mathrm{HydA}$ and $c s$ HydA in batches of 8 and 12, the number of variants of each enzyme isolated by the genetic selection. We used the point mutation spectrum provided by Agilent for the GeneMorph II kit and a total frequency of 4.5 mutations $/ \mathrm{kb}$. Nonsilent mutations were grouped by charge of the original and mutant amino acid (i.e. a positive to neutral substitution). Statistical $95 \%$ confidence intervals for the null distribution were derived from the size of each charge change group across simulated replicates.

\section{Results and Discussion}

\section{Design for hydrogenase-dependent growth}

Figure 1 details the synthetic pathway designed for our selection and expressed in E. coli. An exogenous FeFehydrogenase consumes $\mathrm{H}_{2}$ and reduces ferredoxin. Ferredoxin donates electrons to sulfite reductase for the reduction of sulfite to sulfide. Sulfide serves in the host as an indispensible sulfur source for cysteine biosynthesis.

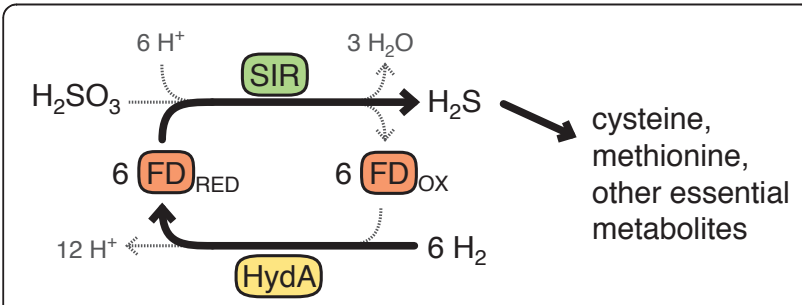

Figure $1 \mathrm{~A}$ synthetic pathway linking hydrogenase activity to host viability. A hydrogenase enzyme (HydA) consumes $\mathrm{H}_{2}$ and reduces ferredoxin $(F D)$, a redox carrier protein. Ferredoxin then donates electrons to a plant-type sulfite reductase (SIR), which reduces sulfite to sulfide. With the native sulfite reductase deleted, this pathway becomes the only source of reduced sulfur, an essential metabolic precursor.
Ferredoxin, an electron-carrying iron-sulfur (Fe-S) protein, is the native redox partner of the best-characterized FeFe-hydrogenases[43]. A ferredoxin also receives electrons from photosystem I in plants, suggesting that it could be adapted to mediate light-driven $\mathrm{H}_{2}$ production. We chose ferredoxin as an intermediate with this future application in mind. A ferredoxin homolog, $f d x$, is found in $E$. coli, where it plays an essential role as a scaffold site for iron-sulfur cluster assembly[44]. E. coli does not appear to use ferredoxin as an electron carrier in the metabolic network, instead relying on $\mathrm{NAD}(\mathrm{P}) \mathrm{H}$. We therefore hypothesized that ferredoxin chemistry would be insulated from native metabolism.

The KEGG pathway database[45] identifies three enzymes that produce essential metabolites using ferredoxin as an electron source. Glutamate synthase, nitrite reductase and sulfite reductase activities are all essential for the growth of $E$. coli in minimal medium. The native bacterial enzymes draw electrons from NADPH to produce glutamate, ammonia and sulfide, respectively. The analogous enzymes in plants yield the same products while drawing electrons from ferredoxin, a common redox carrier in those species. While all three products are indispensable for $E$. coli viability, sulfide is consumed in the smallest molar quantity[46]. We therefore chose to employ sulfite reductase, reasoning that the small metabolic requirement would afford more tolerance for suboptimal performance of the heterologous pathway.

Sulfite reductase is not essential on cysteine-containing rich media, but it becomes essential on selective media containing only oxidized sulfur sources such as sulfate or sulfite. In the absence of the native $E$. coli NADPH-dependent sulfite reductase, $c y s I$, the synthetic pathway is the only metabolic source of reduced sulfur. If the components of this pathway are insulated from any endogenous electron sources, then hydrogenase activity will also be essential for growth. Increasing $\mathrm{O}_{2}$ concentrations, by inactivating the hydrogenase, will eventually inhibit the ability of host cells to grow on sulfite. This synthetic pathway therefore enables a genetic selection for hydrogenase mutants with an ability to support growth in high $\mathrm{O}_{2}$.

\section{Synthetic ferredoxin-dependent sulfite reduction}

We first sought to establish that the native E. coli BL21 (DE3) sulfite reductase could be replaced with a ferredoxin-dependent pathway (Figure 2A). Deletion of the cysI sulfite reductase did not impair growth on rich media (LB), but eliminated growth on selective media with sulfate as the sole source of metabolizable sulfur. Expression of corn (Zea mays) sulfite reductase (zmSIR) alone, or together with spinach ferredoxin (soFD), failed to rescue growth. This indicated that the E. coli host 
A

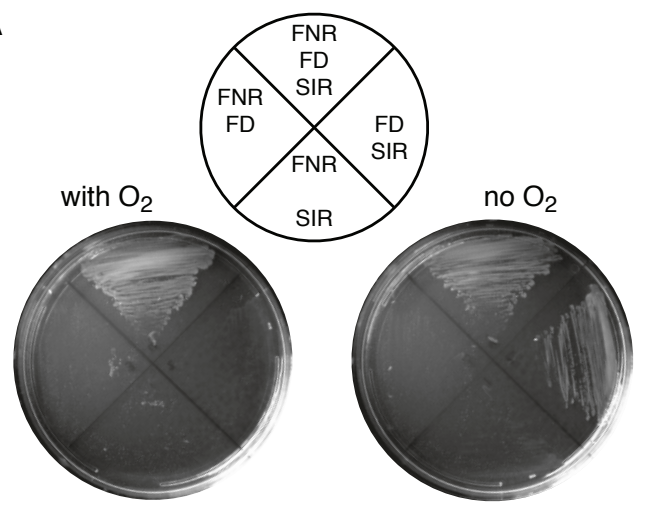

B

Strain Deletions

EW1 cysl

EW2 cyslfpr

EW3 cysl fpr $y d b K$

EW4 cysl fpr ydbK hor

EW5 cysl fpr ydbK hor yeaX

EW6 cysl fpr ydbK hcr yeaX hcaD

EW7 cysl fpr ydbK hor yeaX hcaD frdB

EW11 cysl fpr ydbK hor yeaX hcaD frdB hycE hyaB hybC hyfG

C

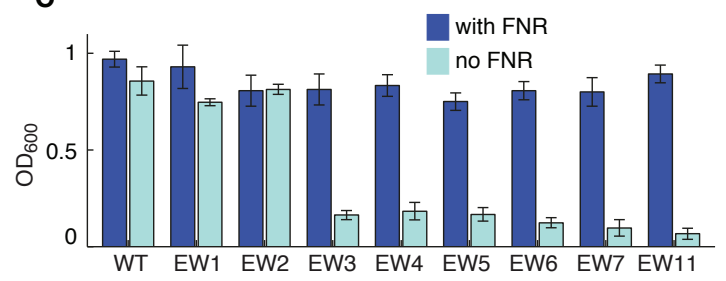

Figure 2 Genetic insulation of the synthetic pathway. A) E. coli BL21(DE3) cys/ cells were transformed with plasmids expressing zmFNR, sOFD and zmSIR. The cys/ deletion conveys a requirement for reduced sulfur, which the heterologous pathway supplies. Cells were grown for 24 hours on selective media with or without atmospheric $\mathrm{O}_{2}$. All three factors were required to rescue growth under aerobic conditions (left plate). Expression of zmFNR was not required under anaerobic conditions (right plate), indicating that soFD was receiving electrons from another source. B) Genetic deletions were targeted to eliminate potential endogenous redox partners for ferredoxin, therefore linking sulfide production specifically to a synthetic electron source. Also deleted were the catalytic subunits of each native hydrogenase, ensuring that only exogenous $\mathrm{H}_{2}$ was present in our system. C) Each deletion strain was transformed with soFD, zmSIR and either zmFNR or an empty plasmid. Growth was measured after 18 hours at $37^{\circ} \mathrm{C}$ under strict anaerobic conditions, as described in the methods. Sequential deletions reduced the nonspecific anaerobic background growth, with the largest effect produced by the deletion of $y d b K$. The final deletion strain, EW11, showed no growth defect in rich media and was used in all later experiments.

provides no interacting source of reduced ferredoxin or ferredoxin-reductase activity under these conditions.

We then provided a heterologous source of reduced ferredoxin in the form of corn-derived (Zea mays)
ferredoxin-NADP ${ }^{+}$reductase $(z m \mathrm{FNR})$. This enzyme links soFD to the endogenous NADPH pool by catalyzing redox exchange between the two electron carriers [47]. FNR requires no maturation factors and is unaffected by $\mathrm{O}_{2}$, therefore it serves as a hydrogenase-independent control source of electrons for our pathway. Expression of $z m$ FNR with soFD and $z m$ SIR rescued growth of the cysI mutant on sulfate in aerobic selective media. The growth rescue required all three factors as well as IPTG induction of the expression plasmids. This result established that the ferredoxin and sulfite reductase components of our pathway were functional and insulated from native metabolism under aerobic conditions.

However, we found that heterologous zmFNR was not required to rescue growth when the selective strain was grown without ambient $\mathrm{O}_{2}$ (Figure 2A). While soFD and $z m S I R$ expression were both still essential, this undesirable background growth indicated that the native metabolic machinery could donate electrons to ferredoxin in anoxic conditions. We did not observe anaerobic growth upon expression of $z m S I R$ alone, indicating that electrons were entering the pathway through soFD.

Anaerobiosis effects global physiological adaptations in E. coli [48]. The transition from respiratory to fermentative growth is accompanied by a drop in cytosolic redox potential concomitant with an excess of reducing equivalents generated by glycolysis. A variety of metabolic pathways are expressed specifically in anaerobic conditions to dispose of electrons through electron acceptors including acetate, fumarate, nitrate and $\mathrm{H}_{2}$. Sulfite in our system represents a high potential electron sink, consistent with the increased tendency for electrons to enter the pathway under these conditions.

To produce the strictest possible connection between the heterologous pathway and strain fitness under selection, we sought to identify and eliminate any endogenous anaerobic electron sources. We selected 6 candidate interacting genes as potential nonspecific electron donors. Candidates were identified based on their homology to known ferredoxin-reducing proteins, with preference given to genes known to be induced anaerobically.

The following six candidate genes were deleted in the BL21(DE3) parent strain: fpr, ydbK, hcr, yeaX, hcaD, $f r d B$. The genes were deleted serially, in a single host strain, in order to expose and eliminate potentially redundant or epistatic interactions of the candidate genes with our pathway (Figure 2B). The fpr gene encodes an anaerobic flavodoxin-NADP ${ }^{+}$reductase[49]. Overexpression of $y d b K$, a putative pyruvate:flavodoxin oxidoreductase, has been shown to drive hydrogenase activity through ferredoxin in E. coli[50]. The hor locus encodes an anaerobically expressed NADH 
oxidoreductase that catalyzes the reduction of the hybrid cluster protein Hcp, an iron-sulfur protein with some homology to ferredoxin[51]. YeaX is a predicted oxidoreductase bearing Fe-S clusters that may associate with the ferredoxin-like YeaW. HcaD encodes a Ferredoxin: $\mathrm{NAD}^{+}$reductase involved in the degradation of 3-phenylpropionate. FrdB is an $\mathrm{Fe}-\mathrm{S}$ protein involved in the anaerobic reduction of fumarate as a terminal electron acceptor. Within the 4-subunit menaquinol-fumarate oxidoreductase complex, FrdB shuttles electrons from the quinone pool to the catalytic flavoprotein $\operatorname{FrdA}[52]$.

We further deleted catalytic subunits of the three characterized endogenous hydrogenases, hycE, hyaB and $h y b C[53]$, and the putative but normally silent hydrogenase $h y f G[54]$. All native $E$. coli hydrogenases are of the $\mathrm{NiFe}$ class, unrelated to the FeFe class and therefore unlikely to interact directly with our pathway. However, eliminating all native hydrogenases ensures that any $\mathrm{H}_{2}$ production or consumption in our system could be attributed to the exogenous hydrogenase.

The knockout strains were transformed with $z m S I R$ and $s o$ FD. Strains also received $z m$ FNR as a synthetic electron source or an empty vector control. As described in the methods, growth was assayed anaerobically overnight in selective liquid media. The results of these experiments are shown in Figure 2.

The sequential knockout of candidate ferredoxininteracting genes from the selection host improved the insulation of the test pathway from the endogenous redox pool. The first deletion, $f p r$, produced no measurable effect on strain growth. The largest contribution to the elimination of background growth came from the knockout of $y d b K$, with further deletions only modestly decreasing the background growth. These results are consistent with the effects of individual genes observed by Agapakis and colleagues[55]. The mutations had no individual or cumulative deleterious effect on strain growth when $z m$ FNR was expressed. We designate as EW11 the final BL21(DE3)-derived strain, which bears the following complete genotype: $E$. coli $\mathrm{B} \mathrm{F}^{-} d c m$ ompT hsdS $\left(\mathrm{r}_{\mathrm{B}}{ }^{-} \mathrm{m}_{\mathrm{B}}{ }^{-}\right)$gal $\lambda$ (DE3) cysI fpr ydbK hcr yeaX hcaD frdB hycE hyaB hybC hyfG. All subsequent experiments were performed in EW11 cells.

Sulfide production by our pathway was confirmed spectophotometrically by the formation of methylene blue, as described in the methods. Wild-type BL21 cells, cultured anaerobically in defined medium, produce small amounts of sulfide: $10 \mu \mathrm{M}( \pm 10$ at $95 \%$ confidence). No sulfide was detected in cultures of EW11 host cells, consistent with the deletion of cysI. Expression of soFD and $z m S I R$ in EW11 resulted in sulfide accumulation only to a mean level of $2 \mu \mathrm{M}( \pm 1)$. When zmFNR was also expressed as a source of electrons, sulfide levels increased dramatically to $200 \mu \mathrm{M}( \pm 30)$.
Similarly, when the caHydA hydrogenase and maturation factors were expressed, sulfide levels reached 100 $\mu \mathrm{M}( \pm 27)$. Supplying the hydrogenase with atmospheric $\mathrm{H}_{2}$ further raised sulfide production to $160 \mu \mathrm{M}( \pm 17)$. These results are consistent with the design of our pathway as a synthetic source of essential reduced sulfur.

\section{Biochemical hydrogenase $\mathrm{O}_{2}$ tolerance in situ}

We sought to initiate our selection with a wild-type hydrogenase with the highest possible native activity and $\mathrm{O}_{2}$ tolerance. We reasoned this would improve the probability of evolving an enzyme with properties exceeding those described in nature. This also would allow us to perform our selection in the presence of some $\mathrm{O}_{2}$, reducing the observed anaerobic background growth. Biochemical techniques allow the in vitro determination of purified hydrogenase activity and $\mathrm{O}_{2}$ tolerance[20]. But because genetic selection can be performed only in vivo, we assayed hydrogenase $\mathrm{O}_{2}$ tolerance in cell lysates that approximate the cytosolic context.

E. coli expressing a hydrogenase derived from either Clostridium acetobutylicum (caHydA), Clostridium saccharobutylicum (csHydA), or Chlamydomonas reinhardtii ( $c r H y d A)$, were grown to saturation in liquid culture under strict anaerobiosis. In each case the hydrogenase was coexpressed with the requisite maturation factors HydEF and HydG from C. reinhardtii, which are known to mature clostridial FeFe-hydrogenases[56]. Culture lysates were exposed to $\mathrm{O}_{2}$ for fixed periods of time and remaining hydrogenase activity was measured biochemically, as described in the methods.

The three hydrogenases were found to differ in both $\mathrm{O}_{2}$ tolerance and maximal activity levels, as shown in Figure 3. The anaerobic activities of the clostridial hydrogenases, $c a \mathrm{HydA}$ and $c s \mathrm{HydA}$, were comparable to each other and both substantially higher than the activity of the Chlamydomonas enzyme, crHydA. While our assay controlled for cell density, the in situ context of our system did not account for possible differences in expression level, maturation or folding efficiency. Replacing the $C$. reinhardtii maturation factors with those derived from $C$. acetobutylicum yielded the same in situ activity for all three hydrogenases (not shown). While the in situ assay does not reflect biochemical specific activities, it measures the effective activity in $E$. coli expressing each hydrogenase, the relevant parameter for our genetic selection.

We also observed substantial variation in the natural $\mathrm{O}_{2}$ tolerance of the three enzymes. In each case the inactivation by $\mathrm{O}_{2}$ could be well-described by first-order reaction kinetics, resulting in an exponential decrease of activity with time. Exposure to 0.1 atm $\mathrm{O}_{2}$ partial pressure degraded activity of caHydA with a characteristic 


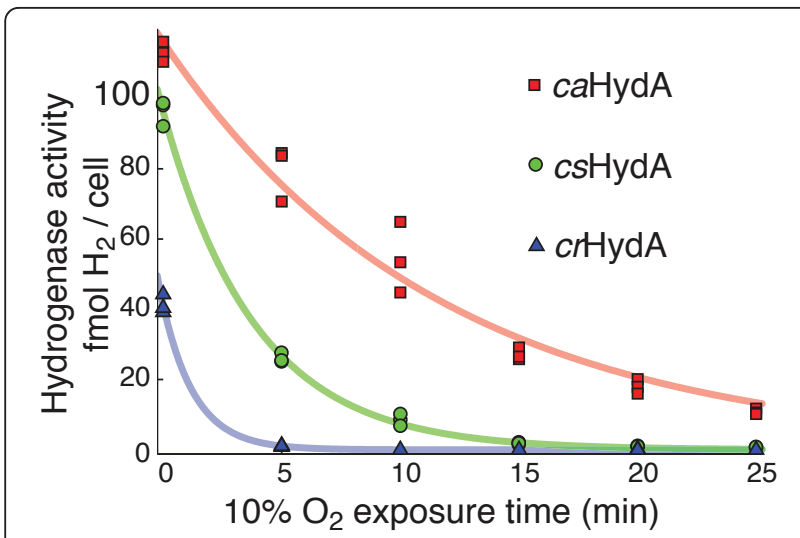

Figure $3 \mathrm{O}_{2}$ tolerance for three hydrogenases in situ. Cells expressing a hydrogenase from either $\mathrm{C}$. acetobutylicum (caHydA), $\mathrm{C}$. saccharobutylicum (csHydA) or C. reinhardtii ( $\mathrm{crHydA}$ ) were exposed to $10 \% \mathrm{O}_{2}$ at $1 \mathrm{~atm}$ total pressure for the indicated times.

Remaining activity was assessed with methyl viologen, as described in the methods. Three biological replicates are plotted for each time point. Significant differences in both maximal activity and $\mathrm{O}_{2}$ tolerance were evident. Hydrogenase inactivation by $\mathrm{O}_{2}$ was well described by first order kinetics, and the best-fit exponential decay curves are shown. The caHydA enzyme exhibited a characteristic half-life of $8( \pm 0.8)$ minutes, the csHydA enzyme 2.7 ( \pm 0.2) minutes and crHydA $1.0( \pm 0.3)$ minutes, including 95\% confidence intervals.

half-life of $8( \pm 0.8)$ minutes, including a $95 \%$ confidence interval. The $c s$ HydA enzyme showed a half-life of 2.7 $( \pm 0.2)$ minutes in $\mathrm{O}_{2}$, and $c r$ HydA activity degraded still more rapidly, with a half-life of $1.0( \pm 0.3)$ minutes. The half-life measurements are intensive biochemical properties of the enzymes in situ, independent of possible differences in hydrogenase expression or maturation levels.

The differences in $\mathrm{O}_{2}$ tolerance are striking. The clostridial enzymes $c a \mathrm{HydA}$ and $c s \mathrm{HydA}$ share $81 \%$ amino acid sequence similarity and nearly identical domain architecture. C. acetobutylicum and C. saccharobutylicum also inhabit similar strictly anaerobic ecological niches[57]. The algal $c r$ HydA is more divergent, only $53 \%$ similar to $c a$ HydA, yet shares the conserved catalytic domain. Chlamydomonas, a eukaryote, exhibits a generally aerobic metabolism. All three enzymes in this experiment receive identically assembled FeFe cluster active sites from shared maturation factors. Yet the halflife of $c a \mathrm{HydA}$ in $\mathrm{O}_{2}$ is twice that of $c s \mathrm{HydA}$ and 8 times that of $c r \mathrm{HydA}$. Because $c a \mathrm{HydA}$ and $c s \mathrm{HydA}$ showed higher activity and superior $\mathrm{O}_{2}$ tolerance, we chose to focus on those enzymes for further study.

\section{The ferredoxin-hydrogenase interaction}

The synthetic pathway we propose operates in two redox steps, hydrogenase to ferredoxin and ferredoxin to sulfite reductase. Each step must be both efficient and well-insulated for the overall design to be effective.
We therefore devised independent in situ assays for each step of the pathway, as depicted in Figure 4A. By evaluating the performance of various ferredoxins in these assays, we sought to identify the ferredoxin best suited for a genetic selection. An optimal ferredoxin would demonstrate a robust interaction with both hydrogenase and sulfite reductase, while remaining insulated from nonspecific interactions with the endogenous redox pool.

We first tested the hydrogenase-ferredoxin connections, employing an independent source of electrons for ferredoxin. In this assay, adapted from Agapakis et al. [55], each ferredoxin is reduced by exogenous pyruvateferredoxin oxidoreductase derived from Desulfovibrio africanus (daPFOR), before transferring electrons to the hydrogenase. The overall activity of this pathway is measured as $\mathrm{H}_{2}$ production in vivo, described in the methods.

The direction of the hydrogenase reaction is the reverse of that sought for the final selection pathway, i.e. it is producing rather than consuming $\mathrm{H}_{2}$. FeFe-

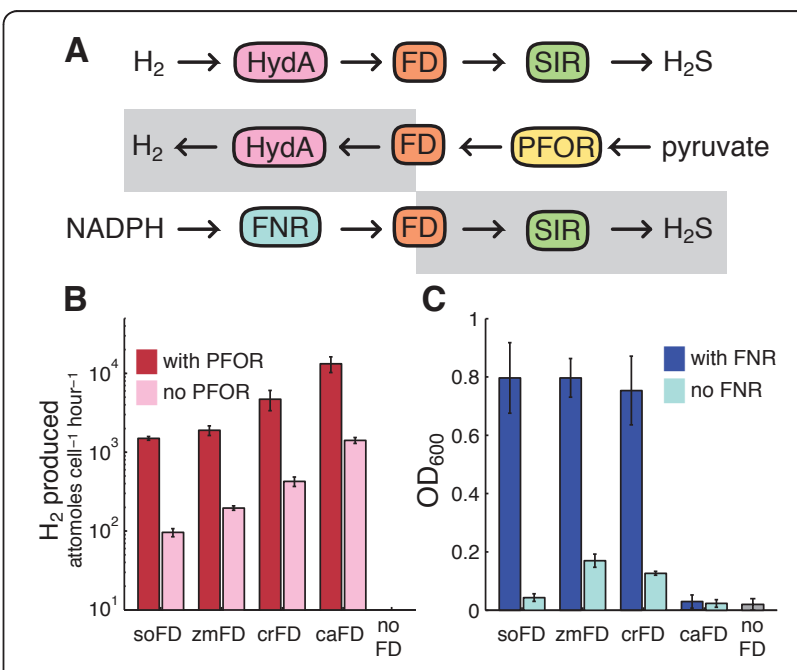

Figure 4 Stepwise optimization of pathway design. A) The proposed pathway operates in two steps, with electrons flowing first from HydA to FD, then from FD to SIR. Substituting PFOR for SIR allows an independent test of the HydA-FD interaction. Substituting FNR for HydA allows an independent test of the FD-SIR interaction. B) PFOR-driven $\mathrm{H}_{2}$ production in vivo with a panel of ferredoxins. $\mathrm{H}_{2}$ production in the presence of PFOR confirms the ability of a ferredoxin to couple with hydrogenase. $\mathrm{H}_{2}$ production in the absence of PFOR suggests that a ferredoxin is reduced by a nonspecific endogenous source, which would tend to confound our genetic selection. C) FNR-rescued growth with a panel of ferredoxins under anaerobic conditions. Growth with FNR confirms the ability of a ferredoxin to couple with SIR. FNR-independent growth suggests that a ferredoxin is not well insulated from endogenous redox sources. All experiments were conducted under anaerobic conditions with the EW11 strain, as described in the methods. Error bars are 95\% confidence intervals. 
hydrogenases are known to operate reversibly, though they generally function to produce $\mathrm{H}_{2}$ in nature[58]. The production of $\mathrm{H}_{2}$ in this case is energetically driven by the highly favorable decarboxylation of pyruvate to acetyl-CoA[59]:

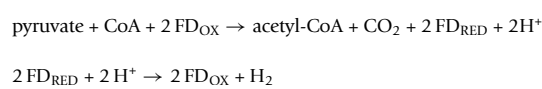

Whereas in the proposed selection pathway, the consumption of $\mathrm{H}_{2}$ is instead driven by the reduction of highly electronegative sulfite:

$$
\begin{aligned}
& 2 \mathrm{FD}_{\mathrm{OX}}+\mathrm{H}_{2} \rightarrow 2 \mathrm{FD}_{\mathrm{RED}}+2 \mathrm{H}^{+} \\
& 1 / 3 \mathrm{SO}_{3}+2 \mathrm{FD}_{\mathrm{RED}}+2 \mathrm{H}^{+} \rightarrow 1 / 3 \mathrm{H}_{2} \mathrm{~S}+2 \mathrm{FD}_{\mathrm{OX}}+\mathrm{H}_{2} \mathrm{O}
\end{aligned}
$$$$
\Delta G^{\prime \prime}=-3.7 \mathrm{~kJ} \mathrm{~mol}^{-1}
$$$$
\Delta G^{\circ \prime}=-202 \mathrm{~kJ} \mathrm{~mol}^{-1}
$$

$\mathrm{H}_{2}$ production from $c a \mathrm{HydA}$, driven by daPFOR and mediated by a panel of candidate ferredoxins is shown in Figure 4B. These data reflect both the ferredoxin$c a \mathrm{HydA}$ interaction and the ferredoxin-daPFOR interaction. Because this assay does not account for variations in the ferredoxin-daPFOR interaction, it could not be used to infer quantitatively the efficiency of electron transfer between a ferredoxin and caHydA. Each ferredoxin had the capacity to facilitate electron transfer to caHydA, as shown by the substantial increase in $\mathrm{H}_{2}$ production relative to cells without exogenous ferredoxin. $\mathrm{No} \mathrm{H}_{2}$ production was detectable without expression of a ferredoxin. Consistent with previously reported results [55], we observed by far the most hydrogenase activity with the native redox partner, $c a \mathrm{FD}$.

Although expression of daPFOR significantly increased $\mathrm{H}_{2}$ production from each ferredoxin, it was not necessary for in vivo hydrogenase activity. $\mathrm{H}_{2}$ production in the absence of $d a \mathrm{PFOR}$ is a measure of nonspecific electron flow from endogenous metabolism to a ferredoxin. Any such flow would tend to weaken the link between hydrogenase activity and host viability in a genetic selection. An optimal ferredoxin partner would produce high hydrogenase activity with $d a$ PFOR and no activity without daPFOR. We found nonspecifically driven $\mathrm{H}_{2}$ production to be significantly less than, yet proportional to, daPFOR-driven production for all ferredoxins.

\section{The ferredoxin-sulfite reductase interaction}

Optimal function of the second step in our pathway requires a robust and specific redox exchange of the mediating ferredoxin with $z m S I R$. We therefore used $z m F N R$ as an independent source of electrons to characterize the interaction between our panel of ferredoxins and the $z m S I R$. Growth was measured in anaerobic selective media for strain EW11 with and without $z m$ FNR expression. The interactions with both $z m$ FNR and $z m$ SIR contribute to the ability of a given ferredoxin to facilitate growth in this system. As above, growth in the absence of $z m$ FNR expression reflects the tendency of a ferredoxin to receive electrons nonspecifically from the endogenous redox pool.

The results of growth assays from the second test pathway are shown in Figure 4C. In contrast to the results of the $\mathrm{H}_{2}$-production assay, we found that the clostridial ferredoxin $c a$ FD showed the worst performance in the sulfite reductase assay, producing no significant growth. Each of the other ferredoxins tested, soFD, $z m \mathrm{FD}$ and $c r \mathrm{FD}$, were able to effectively rescue the sulfide auxotrophy. In the case of the $z m F D$ and $c r \mathrm{FD}$, we also observed significant background growth in the absence of $z m \mathrm{FNR}$ expression, indicating nonspecific interactions of these ferredoxins with native metabolism. The soFD produced no observable background growth under these conditions.

None of the ferredoxins tested performed optimally in both the sulfite reductase and hydrogenase interaction assays. In both cases the differences in performance may be attributed to the distinction between plant-type and bacterial-type ferredoxins. The $s o \mathrm{FD}, z m \mathrm{FD}$ and $c r \mathrm{FD}$ proteins all belong to the plant-type class of ferredoxins. These proteins carry electrons in a characteristic $\mathrm{Fe}_{2} \mathrm{~S}_{2}$ active center[60]. In contrast, $c a \mathrm{FD}$ is a bacterial-type ferredoxin with a $\mathrm{Fe}_{4} \mathrm{~S}_{4}$ cluster[61]. Plant and bacterial ferredoxins share structural and sequence homology $[62,63]$ and can functionally substitute for one another in some cases[64]. However, it seems likely that the relative divergence of bacterial $c a \mathrm{FD}$ precludes an interaction with either $z m \mathrm{FNR}$ or $z m \mathrm{SIR}$, both of which natively pair with plant-type ferredoxins.

We also noted an apparent tendency to higher background activities for ferredoxins with higher redox potentials. Reactions with electrons from the endogenous redox pool may become more thermodynamically favorable as the redox potential of the ferredoxin increases. Among the plant-type ferredoxins the soFD, with a redox potential of $-420 \mathrm{mV}$ [47], showed the lowest nonspecific activity in both assays. The $z m \mathrm{FD}$ at $-345 \mathrm{mV}[47]$ and $c r F D$ at $-390 \mathrm{mV}[65]$, exhibited higher backgrounds. This is also consistent with the theory that ferredoxin interactions are governed by $\mathrm{Fe}-\mathrm{S}$ cluster redox potentials[33,66].

We chose soFD as a best functional compromise for the design requirements of our pathway. This ferredoxin clearly demonstrates an ability to function in both redox steps, and showed the least nonspecific activity in each. It is also one of the biochemically best characterized ferredoxins and a model for ferredoxin-photosystem interactions[67].

\section{$\mathrm{O}_{2}$ sensitivity of hydrogenase-rescued $E$. coli}

We next characterized in situ the behavior of the complete synthetic rescue pathway incorporating soFD, 
$z m$ SIR and a hydrogenase electron source. In particular, we sought to quantify the effect of $\mathrm{O}_{2}$ on the growth of the selection strain in conditions as similar as possible to those that would be encountered in a genetic selection. Strain EW11 expressing soFD, zmSIR, and hydrogenase maturation factors was transformed with either caHydA, csHydA, or crHydA. Cells were plated at low density on selective plates under custom atmospheres with varying $\mathrm{O}_{2}$ pressures. Growth was quantified by measuring the size of colonies formed after three days, as described in the methods.

The dose-response relationship of $\mathrm{O}_{2}$ with various selection strains is depicted in Figure 5. Negative control strains expressing only soFD, $z m \mathrm{SIR}$, and maturation factors showed no measurable growth under any atmosphere (Figure 5A). Positive control strains expressing the $\mathrm{O}_{2}$-tolerant $z m \mathrm{FNR}$ as an electron source showed robust growth under all conditions. Growth for the positive control tended to increase with increasing $\mathrm{O}_{2}$, consistent with the energetic advantages of aerobic metabolism in E. coli.

Hydrogenase-rescued strains showed $\mathrm{O}_{2}$-dependent growth (Figure 5B-D). For each hydrogenase, growth was the best in $0 \% \mathrm{O}_{2}$ and decreased monotonically until almost no growth was detectable in $10 \% \mathrm{O}_{2}$. Growth supported by a hydrogenase was always less than that observed with $z m \mathrm{FNR}$, with colonies less than half as large forming even under strict anaerobiosis. The
caHydA enzyme was the most effective hydrogenase at supporting growth over all conditions, followed by csHydA and $c r$ HydA. This ordering is consistent with the in situ biochemical properties we determined previously. Interestingly, we detected only weak differences in the $\mathrm{O}_{2}$-dependent growth profiles of the hydrogenases relative to the differences in their in vivo activity levels and $\mathrm{O}_{2}$ tolerance. For example, caHydA shows roughly two-fold higher activity and an eight-fold longer half-life than $c r$ HydA. Yet the strain rescued with crHydA produced colonies only about $30 \%$ smaller and reached $50 \%$ growth inhibition at the same $\mathrm{O}_{2}$ level.

Although growth in this assay was strictly dependent on hydrogenase expression, we found that growth did not require the addition of $\mathrm{H}_{2}$ to the atmosphere. Larger colonies were produced in the presence of $\mathrm{H}_{2}$ with all hydrogenases at most $\mathrm{O}_{2}$ levels, yet significant growth was still observed upon replacement of $\mathrm{H}_{2}$ with $\mathrm{N}_{2}$. Representative images illustrating the effect of $\mathrm{H}_{2}$ and $\mathrm{O}_{2}$ on colony size are shown in Figure $5 \mathrm{E} . \mathrm{H}_{2}$-independent growth was more $\mathrm{O}_{2}$-sensitive, reaching $50 \%$ inhibition at roughly $2 \%$ ambient $\mathrm{O}_{2}$ for all hydrogenases, against $5 \%$ for $\mathrm{H}_{2}$-supported growth. When supplied with $\mathrm{H}_{2}$, strains expressing respectively caHydA, $c s \mathrm{HydA}$ and $c r$ HydA were half-maximally inhibited by $\mathrm{O}_{2}$ levels of $5.2 \%( \pm 0.5), 5.7 \%( \pm 0.4)$, and $6.1 \%( \pm 0.7)$, including $95 \%$ confidence intervals. Without $\mathrm{H}_{2}$, the same level of inhibition was respectively reached at $\mathrm{O}_{2}$ levels of $2.5 \%$

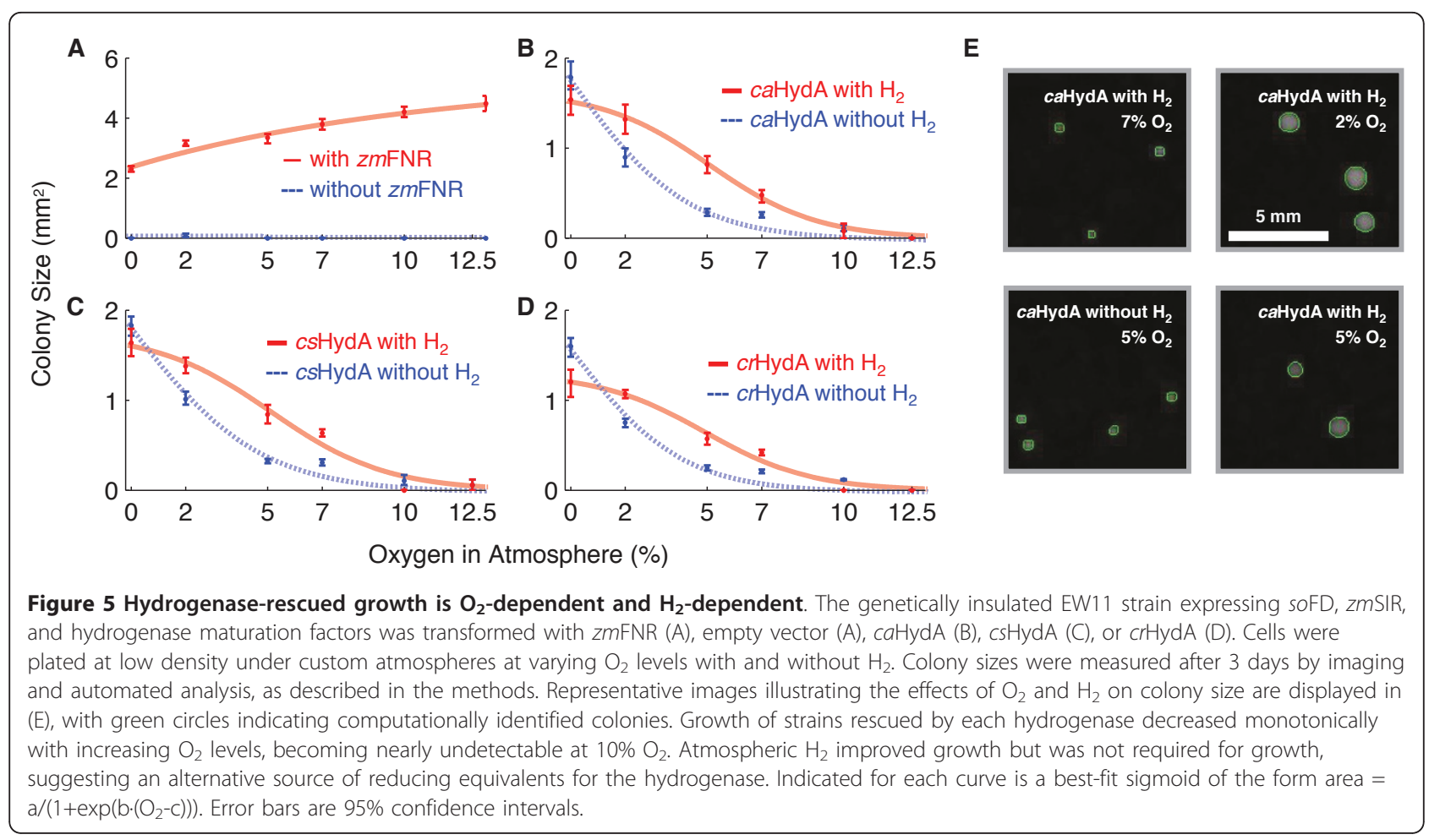


( \pm 0.1$), 2.2 \%( \pm 0.2)$, and $2.3 \%( \pm 0.3)$. This growth could not be attributed to endogenous $\mathrm{H}_{2}$ production, as the EW11 strain lacks all native hydrogenase activity.

Ferredoxin choice strongly affected the growth of the selection host in the growth-response assay. The substitution of $z m \mathrm{FD}$ for soFD in this pathway resulted in much larger colony sizes by area (data not shown). Yet cells expressing $z m F D$ also showed significant nonspecific background growth in the absence of $z m \mathrm{FNR}$ or $c a \mathrm{HydA}$, consistent with results shown in Figure 4. We chose to pursue a genetic selection only in strains demonstrating strictly hydrogenase-dependent growth.

\section{Genetic selection isolates hydrogenases with modified surface properties}

Variant libraries of the $c a \mathrm{HydA}$ and $c s \mathrm{HydA}$ enzymes were produced by error-prone PCR, as described in the methods. These libraries were used to transform EW11 cells expressing soFD, zmSIR and the hydrogenase maturation factors HydEF and HydG. Transformed cells were grown on selective media plates for 4 days under $10 \% \mathrm{O}_{2}$, a non-permissive atmosphere for cells rescued by a wild-type hydrogenase.
Colonies that appeared on the selection plates after incubation were restreaked twice onto selective media. One restreak was regrown under a selective atmosphere at $37^{\circ} \mathrm{C}$ for 4 days, the second was grown on identical plates in open air $\left(\sim 21 \% \mathrm{O}_{2}\right)$. Colonies growing in open air were considered false positives, while colonies growing only in the selective atmosphere were considered candidates to host $\mathrm{O}_{2}$-tolerant hydrogenases. The hydrogenase expression plasmid was isolated from candidate colonies and retransformed into naïve selection hosts. Retransformed hosts were restreaked selectively as before to verify plasmid-linked, hydrogenase-dependent growth.

Our genetic selection isolated twenty-three hydrogenases that passed all restreak and retransformation tests, containing a total of 110 nonsilent point mutations. These variants were sequenced and tested in vitro for hydrogenase activity as described in the methods. Of the twenty-three hydrogenases tested, only two retained full activity. A further nine hydrogenases retained some $\mathrm{H}_{2}$ evolution activity. The largest group of mutants, 12 of the 23 , produced no detectable $\mathrm{H}_{2}$. The locations of the mutations to the $c a \mathrm{HydA}$ and $c s \mathrm{HydA}$ hydrogenase structures are shown in Figure 6. Full sequence and
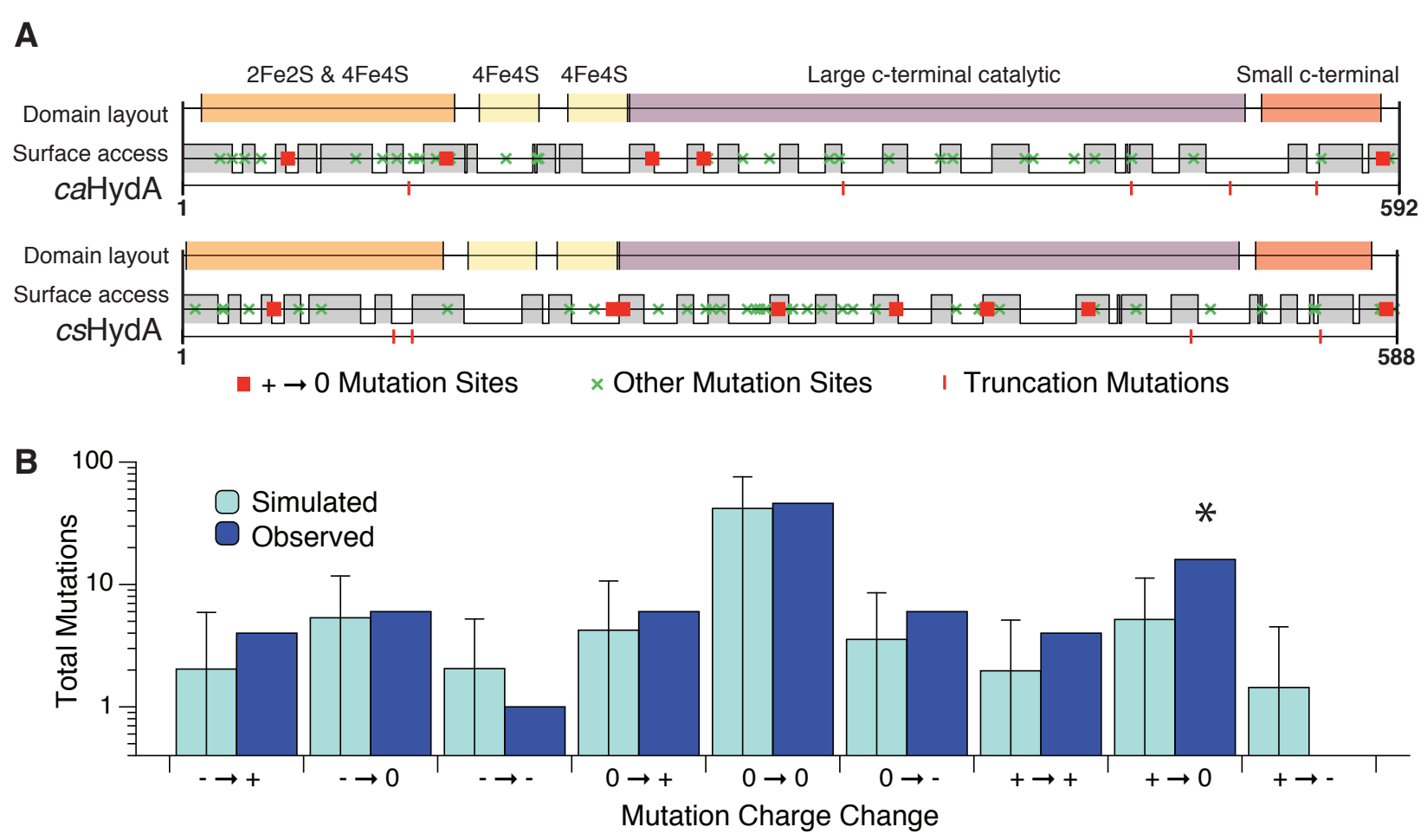

Figure 6 Point mutations isolated by genetic selection. A) Location of 110 nonsilent point mutations from 21 clones. Red squares indicate mutations that neutralize a positively charged residue, green xs mark mutations of all other classes, vertical lines indicate stop codons. Also indicated are the known hydrogenase structural domains and surface-accessible domains that were inferred as described in the methods. B) The observed and expected frequency of mutations by charge change class. Nonsilent mutations were grouped by the charges of both the original and mutant amino acid. Monte Carlo simulations, described in the methods, produce the expected frequency of each charge change class. As indicated by an asterisk, mutations in which a positively charged residue is replaced with a neutral are overrepresented $\left(p-v a l u e: 1.7 \cdot 10^{-3}\right)$. Error bars are $95 \%$ confidence intervals. 
activity data for the mutants are provided in additional file 3.

Seven of the partially functional hydrogenases retained complete structures, containing only point mutations. However, two of the partially functional hydrogenases were truncated by stop codons introduced into their coding sequences. The $c s \mathrm{HydA}$ variant BB22 lacked 33 residues, removing part of the catalytic domain, yet possessed $\approx 5 \%$ of wild-type activity. The caHydA mutant BB05 lacked 82 residues yet still produced detectable $\mathrm{H}_{2}$. To our knowledge, this is the first report that such a severely truncated hydrogenase, lacking the small $\mathrm{C}$ terminal subunit, remains capable of $\mathrm{H}_{2}$ production activity and electron transfer.

Five of the $\mathrm{H}_{2}$-nonproducing hydrogenase mutants displayed only point mutations, while seven showed truncated catalytic domains. Interestingly, four of these seven mutants completely lacked the catalytic domain, containing only the $\mathrm{N}$-terminal ferredoxin-like domains. The most truncated mutant that passed the selection, BB12, retains only 103 of 574 residues, and contains at most two of the four ferredoxin-like domains normally present.

A recurring motif was the modification of positive charges, as illustrated in Figure 6. Of the 110 nonsilent point mutations identified by the assay, 18 altered lysine residues. Of these 18,4 were mutated to arginine: retaining the positive charge of the lysine residue, but substituting a larger side chain. An additional 5 lysine residues were mutated to asparagine, changing the charge to the residue to neutral. Residue 390 was mutated twice, once to isoleucine and once to asparagine, in both cases neutralizing the positive charge. Monte Carlo simulations, as described in the methods, confirmed that mutations neutralizing a positively charged residue were statistically enriched among our mutants ( $\mathrm{p}$-value: $1.7 \cdot 10^{-3}$ ). Because each isolated variant contains multiple substitutions, we were not able to attribute functional changes to individual point mutations.

\section{Conclusions}

The genetic selection for $\mathrm{O}_{2}$ tolerance produced no hydrogenases with $\mathrm{O}_{2}$ tolerance exceeding that of the wild-type, and only one with a comparable activity level. Given the observed widespread loss of $\mathrm{H}_{2}$-production activity, we speculate that the mutants identified by genetic selection confer growth by enhancing $\mathrm{H}_{2}$-independent electron transfer to ferredoxin. Consistent with this hypothesis are the results of Figure 5, indicating that hydrogenase, but not $\mathrm{H}_{2}$, is essential for growth under selection.

We found significant enrichment of mutations neutralizing positive surface charges of the hydrogenase.
Electrostatic forces are known to have an important role in the kinetics and specificity of intermolecular interactions $[68,69]$. Ferredoxin proteins such as those used in our pathway display numerous and conserved negatively charged surface residues, which are thought to govern the specific recognition of various ferredoxin redox partners[66]. Site-directed mutagenesis of lysine residues on the surface of Anabaena FNR was found to block interaction with its native ferredoxin[70]. Our selection pathway employs a non-native pairing of spinach ferredoxin and clostridial hydrogenase, invoking suboptimally coadapted electrostatic interactions. The mutation of surface lysines may enhance ferredoxin-hydrogenase charge complementarity[71]. This could allow for more efficient electron transfer to ferredoxin, an essential activity for host viability.

Our selection also isolated a number of highly truncated hydrogenase variants which were found to retain some function. Variants BB22 and BB05 lacked portions of the small $\mathrm{C}$-terminal hydrogenase subunit but were still competent for $\mathrm{H}_{2}$ production. Similarly truncated putative hydrogenases have been identified in the termite hindgut metagenome[72]. Even more severely truncated variants showed no hydrogenase activity, but were nevertheless capable of rescuing growth. Variant BB09, for example, retained only the $\mathrm{N}$-terminal ferredoxinlike domains, which were nevertheless sufficient to facilitate electron transfer to our synthetic pathway. Future work to identify the minimal structural elements required for hydrogenase function may help to structurally integrate the enzymes with designed electron flows.

Our pathway allows $\mathrm{O}_{2}$-tolerant electron sources such as $z m$ FNR to be distinguished from $\mathrm{O}_{2}$-sensitive sources such as caHydA by their effects on host fitness. Therefore an $\mathrm{O}_{2}$-tolerant hydrogenase, once produced, could in principle be isolated using our selection. That no such hydrogenase was found suggests that other mutations exist to alter hydrogenase redox activity independently of the described $\mathrm{O}_{2}$-sensitive catalytic core[26]. Mutations of this sort may be more common than those specifically altering properties of the active site. The evolution of $\mathrm{O}_{2}$ tolerance may also require more simultaneous mutations than were sampled here, or more extensive structural alterations. The structural features that optimize $\mathrm{O}_{2}$ tolerance might also change when the direction of hydrogenase activity favors consumption versus production. Future efforts may benefit from combining genetic selection with high-throughput techniques to biochemically characterize hydrogenases, currently in development[73].

The data presented in Figure 5 suggest that each hydrogenase can be reduced by an unknown endogenous electron source other than $\mathrm{H}_{2}$. This electron source is eliminated by $\mathrm{O}_{2}$, but apparently through a different 
mechanism than that which directly inactivates the catalytic H-cluster[26]. Such a model would explain the apparent discrepancy between our in vivo and in vitro $\mathrm{O}_{2}$ tolerance assays. While Figure 2 shows different kinetics for the $\mathrm{O}_{2}$ inactivation of each hydrogenase in vitro, Figure 5 shows all three enzymes support comparable $\mathrm{O}_{2}$-tolerant growth. Hydrogenase activity in our system might also be limited by $\mathrm{O}_{2}$ sensitivity of the maturation factors, rather than the mature enzymes. To our knowledge, potential interactions of HydEFG with $\mathrm{O}_{2}$ have not yet been directly examined. An in vivo selection system would become even more valuable in such a case, as mutagenesis and selection could naturally be extended to the maturation factors.

We have shown that engineering can successfully insulate a synthetic electron transfer pathway from the endogenous E. coli redox pool. Minimizing losses to the cell through insulation of an artificial pathway allows more rational control of an engineered metabolic flux. We have demonstrated the use of convenient in vivo assays to validate isolated components of a synthetic $\mathrm{H}_{2}$ metabolism. The results of our assays revealed trade-offs in the choice of pathway components, allowing compromises to meet design goals. Finally, we have successfully tied an essential part of cellular metabolism, the synthesis of cysteine, to hydrogenase activity. By eliminating or disabling this activity with $\mathrm{O}_{2}$, we can halt cellular metabolism. These results demonstrate the utility of this pathway in a genetic selection for $\mathrm{O}_{2}$-tolerant hydrogenases. We anticipate that future work to characterize the $\mathrm{H}_{2}$-independent hydrogenase activity, and to optimize ferredoxin-hydrogenase electron transfer, will allow for more strict selection of $\mathrm{H}_{2}$ catalysts with desired properties.

\section{Additional material}

Additional file 1: Vector sequences. Contains complete sequences for all vectors used in this study and described in table 1.

Additional file 2: Media recipes. Contains exact formulations of the selective and induction media used in these experiments.

Additional file 3: Mutant summaries. Contains mutation, truncation and activity data for all mutants isolated in this work.

\section{List of Abbreviations}

ca: Clostridium acetobutylicum; cr: Chlamydomonas reinhardtii; cs: Clostridium saccharobutylicum; da: Desulfovibrio africanus; FNR: Ferredoxin-NADPH reductase; HydA: Hydrogenase; PFOR: Pyruvate-ferredoxin oxidoreductase; SIR: Sulfite reductase; so: Spinacia oleracea; zm - Zea mays.

\section{Acknowledgements}

We thank Daniel Ducat and Devin Burrill for manuscript revisions. David Savage, Zeev Waks, and Jeffrey Way and the Silver lab provided useful discussions. Remy Chait and Laura Stone assisted with image acquisition. Bruno Afonso assisted with image analysis. Andrew Bergman aided parallelized computations on the HMS Orchestra Cluster. Jim Horn constructed experimental apparatus. Funding was provided by NSF graduate research fellowships to EHW and CMA, an NSF SynBERC fellowship to PMB, and an NRSA post-doctoral fellowship to BB. Research was supported by Army Research Office Award No. W911NF-09-1-0226.

\section{Author details}

'Department of Systems Biology, Harvard Medical School, Boston MA 02115, USA. ${ }^{2}$ Wyss Institute, Harvard University, Boston MA 02115, USA.

\section{Authors' contributions}

EHW designed experiments and drafted the manuscript. EHW, BB, CMA, PMB and $\mathrm{GG}$ performed experiments. EHW, BB, CMA, PMB, GG and PAS analyzed data. All authors read and approved the final manuscript.

\section{Competing interests}

EHW, PMB, CMA, and PAS are inventors of International Patent Application No. PCT/US2009/058361, "In-Vivo Selection System For ID Iron (FEFE) Hydrogenase Properties."

Received: 19 January 2011 Accepted: 26 May 2011

Published: 26 May 2011

\section{References}

1. Vignais PM, Billoud B: Occurrence, classification, and biological function of hydrogenases: an overview. Chem Rev 2007, 107:4206-4272.

2. Hambourger M, Kodis G, Vaughn MD, Moore GF, Gust D, Moore AL, Moore TA: Solar energy conversion in a photoelectrochemical biofuel cell. Dalton Trans 2009, 9979-9989.

3. Blackburn JL, Svedruzic D, Mcdonald TJ, Kim Y, King PW, Heben MJ: Raman spectroscopy of charge transfer interactions between single wall carbon nanotubes and [FeFe] hydrogenase. Dalton Trans 2008, 5454-5461.

4. Reisner E, Powell DJ, Cavazza C, Fontecilla-Camps JC, Armstrong FA: Visible light-driven $\mathrm{H}(2)$ production by hydrogenases attached to dye-sensitized TiO(2) nanoparticles. J Am Chem Soc 2009, 131:18457-18466.

5. Benemann JR, Berenson JA, Kaplan NO, Kamen MD: Hydrogen Evolution by a Chloroplast-Ferredoxin-Hydrogenase System. Proc Natl Acad Sci USA 1973, 70:2317-2320.

6. Ihara M, Nishihara $H$, Yoon $K$, Lenz $O$, Friedrich B, Nakamoto $H$, Kojima K Honma D, Kamachi T, Okura I: Light-driven hydrogen production by a hybrid complex of a [NiFe]-hydrogenase and the cyanobacterial photosystem I. Photochem Photobiol 2006, 82:676-682.

7. Calusinska M, Happe T, Joris B, Wilmotte A: The surprising diversity of clostridial hydrogenases: a comparative genomic perspective. Microbiology 2010, 156:1575-1588.

8. Posewitz M, King P, Smolinski S, Smith R, Ginley A, Ghirardi M, Seibert M: Identification of genes required for hydrogenase activity in Chlamydomonas reinhardtii. Biochem Soc Trans 2005, 33:102-104.

9. King PW, Posewitz MC, Ghirardi ML, Seibert M: Functional studies of [FeFe] hydrogenase maturation in an Escherichia coli biosynthetic system. $J$ Bacteriol 2006, 188:2163-2172.

10. Brenner MP, Bildsten L, Dyson F, Fortson N, Garwin R, Grober R, Hemley R, Joyce $\mathrm{G}$, Katz J: Engineering Microorganisms for Energy Production. Washington DC: Department of Energy; 2006.

11. Armstrong FA: Dynamic electrochemical experiments on hydrogenases. Photosynth Res 2009, 102:541-550.

12. Maness P, Smolinski S, Dillon A, Heben M, Weaver P: Characterization of the oxygen tolerance of a hydrogenase linked to a carbon monoxide oxidation pathway in Rubrivivax gelatinosus. Appl Environ Microbiol 2002, 68:2633.

13. Gogotov I, Zorin N, Serebriakova L, Kondratieva E: The properties of hydrogenase from Thiocapsa roseopersicina. Biochimica et Biophysica Acta (BBA)-Enzymology 1978, 523:335-343.

14. Kovács K, Fodor B, Kovács Á, Csanádi G, Maróti G, Balogh J, Arvani S, Rákhely G: Hydrogenases, accessory genes and the regulation of [NiFe] hydrogenase biosynthesis in Thiocapsa roseopersicina. International Journal of Hydrogen Energy 2002, 27:1463-1469.

15. Burgdorf $T$, Lenz $O$, Buhrke $T$, van der Linden $E$, Jones $A$, Albracht $S$, Friedrich B: [NiFe]-hydrogenases of Ralstonia eutropha H16: modular enzymes for oxygen-tolerant biological hydrogen oxidation. J Mol Microbiol Biotechnol 2005, 10:181-196. 
16. Parkin A, Goldet G, Cavazza C, Fontecilla-Camps JC, Armstrong FA: The Difference a Se Makes? Oxygen-Tolerant Hydrogen Production by the [NiFeSe]-Hydrogenase from Desulfomicrobium baculatum. J Am Chem Soc 2008, 130:13410-13416.

17. Ghirardi ML, Posewitz MC, Maness P, Dubini A, Yu J, Seibert M: Hydrogenases and hydrogen photoproduction in oxygenic photosynthetic organisms. Annual review of plant biology 2007, 58:71-91.

18. Frey M: Hydrogenases: hydrogen-activating enzymes. Chembiochem 2002, 3:153-160

19. Sun J, Hopkins RC, Jenney FE, Mcternan PM, Adams MWW: Heterologous Expression and Maturation of an NADP-Dependent [NiFe]-Hydrogenase: A Key Enzyme in Biofuel Production. PLOS ONE 2010, 5:e10526.

20. Baffert C, Demuez M, Cournac L, Burlat B, Guigliarelli B, Bertrand P, Girbal L, Léger C: Hydrogen-activating enzymes: activity does not correlate with oxygen sensitivity. Angew Chem Int Ed Engl 2008, 47:2052-2054.

21. Cangelosi GA, Wheelis ML: Regulation by molecular oxygen and organic substrates of hydrogenase synthesis in Alcaligenes eutrophus. J Bacteriol 1984, 159:138-144.

22. Appel J, Phunpruch S, Steinmüller K, Schulz R: The bidirectional hydrogenase of Synechocystis sp. PCC 6803 works as an electron valve during photosynthesis. Arch Microbiol 2000, 173:333-338.

23. Buhrke $T$, Lenz $O$, Krauss N, Friedrich B: Oxygen tolerance of the $\mathrm{H} 2$ sensing [NiFe] hydrogenase from Ralstonia eutropha $\mathrm{H} 16$ is based on limited access of oxygen to the active site. J Biol Chem 2005, 280:23791-23796.

24. Dementin $S$, Leroux F, Cournac $L$, de Lacey AL, Volbeda A, Léger $C$, Burlat $B$, Martinez N, Champ S, Martin L, Sanganas O, Haumann M, Fernandez VM, Guigliarelli B, Fontecilla-Camps JC, Rousset M: Introduction of methionines in the gas channel makes [NiFe] hydrogenase aero-tolerant. J Am Chem Soc 2009, 131:10156-10164.

25. Stiebritz MT, Reiher M: Theoretical study of dioxygen induced inhibition of [FeFe]-hydrogenase. Inorg Chem 2009, 48:7127-7140.

26. Stripp ST, Goldet G, Brandmayr C, Sanganas O, Vincent KA, Haumann M, Armstrong FA, Happe T: How oxygen attacks [FeFe] hydrogenases from photosynthetic organisms. Proc Natl Acad Sci USA 2009, 106:17331-17336.

27. Arnold FH: Design by directed evolution. Acc Chem Res 1998, 31:125-131.

28. Tracewell CA, Arnold FH: Directed enzyme evolution: climbing fitness peaks one amino acid at a time. Curr Opin Chem Biol 2009, 13:3-9.

29. Stapleton JA, Swartz JR: A cell-free microtiter plate screen for improved [FeFe] hydrogenases. PLOS ONE 2010, 5:e10554.

30. Phillips I, Silver PA: A New Biobrick Assembly Strategy Designed for Facile Protein Engineering. 2006, 1-6[http://hdl.handle.net/1721.1/32535].

31. Nagy LE, Meuser JE, Plummer S, Seibert M, Ghirardi ML, King PW, Ahmann D, Posewitz MC: Application of gene-shuffling for the rapid generation of novel [FeFe]-hydrogenase libraries. Biotechnol Lett 2007, 29:421-430.

32. Pieulle $L$, Magro V, Hatchikian EC: Isolation and analysis of the gene encoding the pyruvate-ferredoxin oxidoreductase of Desulfovibrio africanus, production of the recombinant enzyme in Escherichia coli, and effect of carboxy-terminal deletions on its stability. J Bacteriol 1997, 179:5684-5692.

33. Guerrini $O$, Burlat B, Léger C, Guigliarelli B, Soucaille P, Girbal L: Characterization of two 2[4Fe4S] ferredoxins from Clostridium acetobutylicum. Curr Microbiol 2008, 56:261-267.

34. Baba T, Ara T, Hasegawa M, Takai Y, Okumura Y, Baba M, Datsenko KA, Tomita M, Wanner BL, Mori H: Construction of Escherichia coli K-12 inframe, single-gene knockout mutants: the Keio collection. Mol Syst Biol 2006, 2, 2006.0008.

35. Zhang Y, Buchholz F, Muyrers JP, Stewart AF: A new logic for DNA engineering using recombination in Escherichia coli. Nat Genet 1998, 20:123-128.

36. Cline J: Spectrophotometric determination of hydrogen sulfide in natural waters. Limnology and Oceanography 1969, 14:454-458.

37. Postgate J: Nitrogen Fixation. 3 edition. New York, NY: Cambridge University Press; 1998.

38. Wimpenny JW, Coombs JP: Penetration of oxygen into bacterial colonies. J Gen Microbiol 1983, 129:1239-1242.

39. Peters AC, Wimpenny JW, Coombs JP: Oxygen profiles in, and in the agar beneath, colonies of Bacillus cereus, Staphylococcus albus and Escherichia coli. J Gen Microbiol 1987, 133:1257-1263.
40. Kiefer F, Arnold K, Kunzli M, Bordoli L, Schwede T: The SWISS-MODEL Repository and associated resources. Nucleic Acids Res 2009, 37:D387-92.

41. Pandey AS, Harris TV, Giles LJ, Peters JW, Szilagyi RK: Dithiomethylether as a ligand in the hydrogenase h-cluster. J Am Chem Soc 2008, 130:4533-4540.

42. Yeates TO: Algorithms for evaluating the long-range accessibility of protein surfaces. J Mol Biol 1995, 249:804-815

43. Demuez M, Cournac L, Guerrini O, Soucaille P, Girbal L: Complete activity profile of Clostridium acetobutylicum [FeFe]-hydrogenase and kinetic parameters for endogenous redox partners. FEMS Microbiology Letters 2007, 275:113-121.

44. Nakamura M, Saeki K, Takahashi Y: Hyperproduction of recombinant ferredoxins in escherichia coli by coexpression of the ORF1-ORF2-iscSiscU-iscA-hscB-hs cA-fdx-ORF3 gene cluster. J Biochem 1999, 126:10-18.

45. Kanehisa M, Araki M, Goto S, Hattori M, Hirakawa M, Itoh M, Katayama T, Kawashima S, Okuda S, Tokimatsu T, Yamanishi Y: KEGG for linking genomes to life and the environment. Nucleic Acids Res 2008, 36:D480-4.

46. Feist AM, Henry CS, Reed $J$, Krummenacker M, Joyce AR, Karp PD, Broadbelt $L$, Hatzimanikatis $V$, Palsson $B \varnothing$ : A genome-scale metabolic reconstruction for Escherichia coli K-12 MG1655 that accounts for 1260 ORFs and thermodynamic information. Mol Syst Biol 2007, 3:121.

47. Yonekura-Sakakibara K, Onda Y, Ashikari T, Tanaka Y, Kusumi T, Hase T: Analysis of reductant supply systems for ferredoxin-dependent sulfite reductase in photosynthetic and nonphotosynthetic organs of maize. Plant Physiol 2000, 122:887-894.

48. luchi S, Weiner L: Cellular and molecular physiology of Escherichia coli in the adaptation to aerobic environments. J Biochem 1996, 120:1055-1063.

49. Jenkins CM, Waterman MR: Flavodoxin and NADPH-flavodoxin reductase from Escherichia coli support bovine cytochrome P450c17 hydroxylase activities. J Biol Chem 1994, 269:27401-27408.

50. Akhtar MK, Jones PR: Construction of a synthetic YdbK-dependent pyruvate:H2 pathway in Escherichia coli BL21(DE3). Metab Eng 2009, 11:139-147.

51. Boxhammer S, Glaser S, Kühl A, Wagner AK, Schmidt CL: Characterization of the recombinant Rieske [2Fe-2S] proteins $\mathrm{HcaC}$ and YeaW from $\mathrm{E}$. coli. Biometals 2008, 21:459-467.

52. Cecchini G, Schröder I, Gunsalus RP, Maklashina E: Succinate dehydrogenase and fumarate reductase from Escherichia coli. Biochim Biophys Acta 2002, 1553:140-157.

53. Maeda T, Sanchez-Torres V, Wood TK: Escherichia coli hydrogenase 3 is a reversible enzyme possessing hydrogen uptake and synthesis activities. Appl Microbiol Biotechnol 2007, 76:1035-1042.

54. Self WT, Hasona A, Shanmugam KT: Expression and regulation of a silent operon, hyf, coding for hydrogenase 4 isoenzyme in Escherichia coli. $J$ Bacteriol 2004, 186:580-587.

55. Agapakis CM, Ducat DC, Boyle PM, Wintermute EH, Way JC, Silver PA: Insulation of a synthetic hydrogen metabolism circuit in bacteria. J Biol Eng 2010, 4:3.

56. Böck A, King PW, Blokesch M, Posewitz MC: Maturation of hydrogenases. Adv Microb Physiol 2006, 51:1-71.

57. Keis S, Sullivan JT, Jones DT: Physical and genetic map of the Clostridium saccharobutylicum (formerly Clostridium acetobutylicum) NCP 262 chromosome. Microbiology (Reading, Engl) 2001, 147:1909-1922.

58. Nicolet Y, Cavazza C, Fontecilla-Camps JC: Fe-only hydrogenases: structure, function and evolution. J Inorg Biochem 2002, 91:1-8.

59. Alberty RA: Thermodynamics of biochemical reactions. Hoboken, NJ: John Wiley and Sons; 2003.

60. Fukuyama K: Structure and function of plant-type ferredoxins. Photosynth Res 2004, 81:289-301.

61. Bertini I, Donaire A, Feinberg BA, Luchinat C, Piccioli M, Yuan H: Solution structure of the oxidized 2[4Fe-4S] ferredoxin from Clostridium pasteurianum. Eur J Biochem 1995, 232:192-205.

62. Otaka $E$, Ooi T: Examination of protein sequence homologies: V. New perspectives on evolution between bacterial and chloroplast-type ferredoxins inferred from sequence evidence. J Mol Evol 1989, 29:246-254.

63. Matsubara H, Hase T, Wakabayashi S, K W: Structural and Evolution of Chloroplast- and Bacterial-Type Ferredoxins. UCLA Forum Med Sci 1979, 21:245-266

64. Tagawa K, Arnon Dl: Ferredoxins as electron carriers in photosynthesis and in the biological production and consumption of hydrogen gas. Nature 1962, 195:537-543. 
65. Terauchi AM, Lu S, Zaffagnini M, Tappa S, Hirasawa M, Tripathy JN, Knaff DB, Farmer PJ, Lemaire SD, Hase T, Merchant SS: Pattern of expression and substrate specificity of chloroplast ferredoxins from Chlamydomonas reinhardtii. Journal of Biological Chemistry 2009, 284:25867-25878.

66. Moulis JM, Davasse V: Probing the role of electrostatic forces in the interaction of Clostridium pasteurianum ferredoxin with its redox partners. Biochem 1995, 34:16781-16788.

67. Kovalenko IB, Abaturova AM, Riznichenko GY, Rubin AB: Computer simulation of interaction of photosystem 1 with plastocyanin and ferredoxin. BioSystems 2011, 103:180-187.

68. Mittag T, Kay LE, Forman-Kay JD: Protein dynamics and conformational disorder in molecular recognition. J Mol Recognit 2010, 23:105-116.

69. Davis ME, McCammon JA: Electrostatics in biomolecular structure and dynamics. Chem Rev 1990, 90:509-521.

70. Schmitz S, Martínez-Júlvez M, Gómez-Moreno C, Böhme H: Interaction of positively charged amino acid residues of recombinant, cyanobacterial ferredoxin:NADP+ reductase with ferredoxin probed by site directed mutagenesis. Biochim Biophys Acta 1998, 1363:85-93.

71. Chang CH, King PW, Ghirardi ML, Kim K: Atomic resolution modeling of the ferredoxin:[FeFe] hydrogenase complex from Chlamydomonas reinhardtii. Biophys / 2007, 93:3034-3045.

72. Warnecke $F$, Luginbühl $P$, Ivanova $N$, Ghassemian $M$, Richardson $T H$, Stege JT, Cayouette M, McHardy AC, Djordjevic G, Aboushadi N, Sorek R, Tringe SG, Podar M, Martin HG, Kunin V, Dalevi D, Madejska J, Kirton E, Platt D, Szeto E, Salamov A, Barry K, Mikhailova N, Kyrpides NC, Matson EG, Ottesen EA, Zhang X, Hernández M, Murillo C, Acosta LG, Rigoutsos I, Tamayo G, Green BD, Chang C, Rubin EM, Mathur EJ, Robertson DE, Hugenholtz P, Leadbetter JR: Metagenomic and functional analysis of hindgut microbiota of a wood-feeding higher termite. Nature 2007, 450:560-565.

73. Stapleton JA, Swartz JR: Development of an in vitro compartmentalization screen for high-throughput directed evolution of [FeFe] hydrogenases. PLOS ONE 2010, 5:e15275.

doi:10.1186/1754-1611-5-7

Cite this article as: Barstow et al:: A synthetic system links FeFehydrogenases to essential $E$. coli sulfur metabolism. Journal of Biological Engineering 2011 5:7.

\section{Submit your next manuscript to BioMed Central and take full advantage of:}

- Convenient online submission

- Thorough peer review

- No space constraints or color figure charges

- Immediate publication on acceptance

- Inclusion in PubMed, CAS, Scopus and Google Scholar

- Research which is freely available for redistribution

Submit your manuscript at www.biomedcentral.com/submit
Biomed Central 